\title{
A CONTRARREFORMA dO ENSINO MÉdiO E OS RUMOS DA EDUCAÇÃO PROFISSIONAL NO BRASIL
}

\section{THE COUNTERREFORM OF SECONDARY EDUCATION AND THE DIRECTIONS OF PROFESSIONAL EDUCATION IN BRAZIL}

Shilton Roque dos Santos ${ }^{1}$

Marcio Adriano Azevedo ${ }^{2}$

\section{RESUMO}

O artigo analisa o contexto da contrarreforma do Ensino Médio, suas implicações para a Educação Profissional e sua inserção num quadro maior de contrarreformas que marcam um novo circuito histórico para a Educação Profissional no Brasil. Trata-se de uma pesquisa bibliográfica e documental, que se utiliza das categorias teóricas de hegemonia de Gramsci (1991), bem como do conceito de politecnia de Saviani (1989), da compreensão de Escola Politécnica de Pystrak (2005) e de formação humana integrada de Moura, Lima Filho e Silva (2015), para analisar a Contrarreforma do Ensino Médio paralelamente à reforma trabalhista e a Emenda constitucional de congelamento dos Gastos Públicos e suas implicações para a sociedade brasileira, em especial seus reflexos para a Educação Profissional. Conclui-se que apesar da contrarreforma do Ensino Médio estar alinhada com as demais reformas empreendidas pelo Estado brasileiro e que esta aprofunda um quadro histórico de dualidade na educação brasileira, esse processo, por ser político, por trazer em seu cerne os prolegômenos do pensamento hegemônico com as contradições da lógica capitalista corresponde a um espaço para lutas, resistência e mobilização da sociedade por seus direitos inalienáveis.

Palavras-chave: Ensino Médio; Educação Profissional; Reformas; Mediotec.

\begin{abstract}
The article analyzes the context of the counterreform of secondary education, its implications in professional formation and its insert in the bigger picture of counter reforms that marks a new historical route for Professional Education in Brazil. It is a bibliographical and documentary research that uses Gramsci's theoretical categories of hegemony (1991), as well as Saviani's concept of polytechnics (1989), understanding of the Polytechnic School of Pystrak (2005), and the integrated human formation from Moura, Lima Filho and Silva (2015), to analyze Secondary School Counterreform in paralell to the labor reform and the constitutional amendment for freezing public expenditure and its implications to brazilian society, specially its reflexes to the Professional Education. Regardless of the counterreform of Secondary Education being in line with the other reforms engaged by the brazilian state, that deepens a

\footnotetext{
${ }^{1}$ Mestre em Educação pelo Programa de Pós-Graduação em Educação Profissional do Instituto Federal de Educação, Ciência e Tecnologia do Rio Grande do Norte. Possui graduação em Direito pela Universidade Federal do Rio Grande do Norte (2011), Especialista em Direito Administrativo (2012). Advogado inscrito na OAB/RN sob o número de ordem 10.269. Atualmente é assistente em administração do Instituto Federal de Educação, Ciência e Tecnologia do Rio Grande do Norte e é pesquisador em Avaliação Política, Educação Profissional e Assistência Estudantil.

${ }^{2}$ Pós-Doutor em Sociologia da Educação pela Universidade do Minho/Portugal. Doutor em Educação pelo Programa de Pós-Graduação em Educação da UFRN. Mestrado em Educação pela UFRN. Especialista em Processos Educacionais pela UFRN e graduado em Pedagogia pela UFRN. É professor no Mestrado Acadêmico do Programa de Pós-Graduação em Educação Profissional pelo IFRN
} 
picture of duality in brazilian education, this process, by being political, bringing into its core the prolegomena of hegemonic thinking with the contradictions of the capitalist logic corresponds to a space for fighting, resistance e social mobilization for its inalienable rights.

Keywords: Secondary School; Professional education; Reforms; Mediotec.

\section{APRESENTANDO O OBJETO DE ESTUDO}

Este artigo é resultado dos debates realizados na mesa-redonda: Reforma Educacional no contexto de perda de direitos e precarização da Educação, que foi parte do $10^{\circ}$ Seminário Nacional de Educação do Sindicato Nacional dos Servidores Federais da Educação Básica, Profissional e Tecnológica (Sinasefe) ocorrido em dezembro de 2017, na cidade de Santa Maria, no Rio Grande do Sul. Sendo assim, sua organização reflete a preocupação do maior sindicato dos profissionais da educação profissional pública em nosso país acerca das reformas empreendidas pelo governo federal a partir de 2016.

O momento político em que vivemos no Brasil exige organização e uma leitura adequada da realidade histórica. A delicadeza de tal momento reside em um quadro onde o atual ocupante da cadeira de presidente da República apresenta menos de 3\% de aprovação pública, não tendo sido eleito para esse cargo, e mesmo assim junto a um dos congressos mais conservadores da história do país ${ }^{3}$ tem implementado políticas de retirada de direitos dos trabalhadores e dos cidadãos em geral, tem feito uma das maiores privatizações dos bens públicos e ao mesmo tempo congelou o gasto público tudo isso à revelia do debate político com a população.

A educação é uma das áreas atingidas pelas contrarreformas, e justamente àquela que é constitucionalmente garantida como direito de todo brasileiro, a educação básica, em especial o Ensino Médio, etapa que ainda é um desafio histórico para o país realizar a sua oferta adequada. Esta etapa final da educação básica foi toda transformada por meio de uma Medida Provisória, ou seja, um instrumento que apesar de legal, apresenta um fluxo de aprovação enviesado, pois entra em vigor com sua edição, e só em seguida é debatido no Congresso Nacional. Tal estratégia possibilita que essas mudanças não sejam discutidas de forma adequada pela sociedade, o que parece ser o objetivo desta ação deletéria direcionada À educação dos jovens.

Uma das formas em que o Ensino Médio é ofertado em nosso país é em à integrada a Educação Profissional, sendo esta uma possibilidade de inserção de identidade a esta etapa

3 Segundo o Departamento Intersindical de Assessoria Parlamentar, o atual Congresso eleito é o mais conservador desde a Ditadura Militar, segundo o seu estudo "Radiografia do Novo Congresso". Disponível em: <http://www.diap.org.br/index.php/publicacoes/finish/41 radiografia-do-novo-congresso/2883-radiografia-do-novo-congresso-legislatura-2015-2019-dezembro-de-2014> Acesso em 06 dez. 2017. 
do ensino, que em seu atual momento parece simbolizar apenas uma passagem entre o Ensino Fundamental e o Ensino Superior. Ademais, diante da história do Ensino Médio e da Educação Profissional, bem como do contexto histórico e social do nosso país nesse momento, pode-se afirmar que o Ensino Médio Integrado ainda é um privilégio para poucos, mas, possibilita a inserção dos filhos da classe trabalhadora a uma educação com qualidade referenciada, basta vermos os resultados como o último Exame Nacional do Ensino Médio, onde os Institutos Federais tiveram as maiores notas em 14 estados da federação, apesar dos cortes de orçamento e investimento realizados pelo governo Temer ${ }^{4}$.

A Contrarreforma do Ensino Médio, em ligação com outras medidas do atual governo Michel Temer, apresenta sérias implicações para a Educação Profissional e são essas medidas o alvo de discussão no presente artigo. Discussão esta que terá como base metodológica a pesquisa documental e bibliográfica, e como lente para ver a realidade que rodeia nosso objeto o materialismo-histórico-dialético (MARX, 2008; LUKACS, 2003) que como metodologia valoriza a perspectiva histórica do desenvolvimento da sociedade e assume a condição desta ser cindida em classes que em meio às contradições entre estas são consideradas como motor da história. Para isso utiliza-se as categorias teóricas de hegemonia de Gramsci (1991), bem como o conceito de politecnica de Saviani (1989), a compreensão de Escola Politécnica de Pystrak (2005) e de formação humana integrada de Moura, Lima Filho e Silva (2015). Assim, no sentido formulado por Luxemburgo (2010) sobre reforma e contrarreforma em uma observação contextual do espaço político busca-se dissecar as Contrarreformas do Ensino Médio permeadas pela reforma trabalhista e a Emenda constitucional de congelamento dos Gastos Públicos e suas implicações para a sociedade brasileira, em especial seus reflexos para a Educação Profissional.

\section{REFORMA OU CONTRARREFORMA - ROSA LUXEMBURGO}

Antes da discussão central do nosso trabalho é importante explicar a nossa opção pelo uso do termo contrarreforma, diante do uso comum da expressão reforma para às políticas de retrocesso social que estão sendo formuladas, aprovadas e implementadas pelo governo Temer no Brasil a partir de 2016.

A expressão Reforma ganhou destaque com o debate entre os Socialistas ao final do Século XIX, num período marcado pelo que chamamos de Revisionismo, que é opção teórica e prática de partidos e militantes por abandonar às tarefas revolucionárias como estratégia a

Disponível em: <https://www1.folha.uol.com.br/educacao/2018/01/1950323-apesar-de-cortes-institutos-federais-lideram-nota-doenem-em-14-estados.shtml> Acesso em 31 jan. 2018.

Revista Labor Fortaleza/CE, jul/dez 2018 n² 20, Vol. 01, pp. 78-95 ISSN 1983-5000 
superação do capitalismo e adotarem concepções de adequação a ordem econômico-social vigente como forma de atuação política e transformação social.

Esse debate ganhou centralidade na obra de Rosa Luxemburgo (2010), Reforma ou Revolução na qual a autora se contrapõe às teses de uma das lideranças centrais da Social Democracia Alemã, um dos maiores partidos socialistas daquele período do qual Rosa era parte integrante.

A tese de Bernstein ${ }^{5}$ indicava que graças a vitalidade do capitalismo, que não apresentava sinais de crise, e a possibilidade de conquistas de direitos e melhores condições de vida por parte dos trabalhadores naquele momento histórico a partir das reformas sociais, seria um erro apostar na transformação social via revolução. Então, a via da transformação seria pressionar o poder por reformas sociais possíveis dentro da própria ordem capitalista, com a disputa política dentro das próprias instituições do Estado, que faz parte dessa ordem capitalista.

Luxemburgo (2010) se contrapõe a tal concepção, indicando que as reformas sociais apesar de serem essenciais para a melhoria das condições de vida da classe trabalhadora não podem se constituir como um fim em si mesmas. Para ela a condição de explorados só passaria para a de emancipação humana com a transformação da nossa sociedade. Essa é a tese sobre a qual ela constrói as argumentações ao longo de sua obra, explicando porque não é possível fazer essa transformação completa dentro da ordem capitalista. Portanto, seria importante ter no horizonte da luta a revolução para tal.

Nesse sentido, resgato aqui o conceito de Reforma de Luxemburgo como sendo algo de interesse dos trabalhadores, algo que lhes traga benefício, ainda assim, não sendo o seu desejo final, que é de revolução, transformação. Logo, diante das argumentações traçadas por Luxemburgo e compreendendo que as transformações sociais no contexto brasileiro desse momento conforme o que vêm sendo proposto pelo governo Temer, são políticas de supressão de direitos, de agudização das contradições e condições de vida daqueles que vivem do trabalho em nossa sociedade, portanto, o que o governo brasileiro denomina de reformas, denominaremos de contrarreformas, por suprimir direitos já conquistados e por não permitir a emancipação social dos cidadãos que vivem do trabalho.

\section{O BRASIL DAS CONTRARREFORMAS E DO GOLPE}

A Contrarreforma do Ensino Médio não é uma política isolada e não tem início a partir da edição da Medida Provisória n 746/2016, ela é parte de uma ação sistêmica na

\footnotetext{
$5 \quad$ Outro grande ator político da Social Democracia Alemã, responsável pelo discurso revisionista e reformista, que foi base para as críticas e construção da obra da Rosa Luxemburgo, Reforma ou Revolução (2010).
} 
construção de um quadro muito mais amplo e agudo de retrocesso social e ampliação das desigualdades. Para entendermos os objetivos desta política é necessário entender o que a circunda e qual a motivação dos seus formuladores.

Esta ação é parte de uma série de grandes mudanças estruturais que vêm sendo apresentadas em nosso país por meio de um governo ilegítimo que chegou ao poder através de um golpe político-jurídico-midiático, com apoio das camadas que mais se beneficiam com o quadro de desigualdades sociais do país ${ }^{6}$.

Esse governo assumiu o poder após 14 anos de um circuito histórico marcado pela ocupação da cadeira da presidência pelo Partido dos Trabalhadores e pelo campo popular, marcado por um modelo neodesenvolvimentista. Com esse partido ocorreram avanços em diversas políticas sociais, mas as contradições inerentes ao sistema capitalista também possibilitaram a ampliação dos lucros e do poder das camadas mais ricas, que não tinham interesse na redução das desigualdades. Contraditoriamente, também são essas camadas da sociedade brasileira que exigiram a retirada do governo legitimamente eleito, para implantar com mais velocidade e vigor políticas públicas que os beneficiariam em detrimento de uma maior espoliação das camadas que vivem do trabalho no Brasil.

Tal projeto político, graças a construção de uma imagem de corrupção e de incompetência administrativa, a partir da imprensa hegemônica e do financiamento de novas organizações políticas com discurso pautado no apartidarismo, apoliticidade e combate à corrupção $^{7}$, faz emergir a função da ignorância e com essa engendraram um processo de impeachment da presidente eleita Dilma Roussef. Esse processo cumpriu todas as suas formalidades, porém com uma base material discutível - por isso, considerado como golpe - o que se tornará marca do governo que cumprirá o mandato presidencial até as próximas eleições - legalidade sem legitimidade (MANCE, 2018).

A vitória parlamentar do impeachment inicia um novo ciclo político em nosso país, por um lado uma aliança entre Congresso e Presidência, que aprovam e tramitam na maior brevidade possível e com grande maioria de votos, medidas de retrocesso social como a Emenda Constitucional 95 que congela o gasto público por 20 anos, a Contrarreforma Trabalhista que suprime direitos conquistados historicamente pelos trabalhadores e amplia a possibilidade de exploração e empobrecimento destes e de enriquecimento da classe empresarial, tentava

\footnotetext{
$6 \quad$ Segundo o Instituto Brasileiro de Geografia e Estatística, o $1 \%$ da população com os maiores rendimentos, tem rendimento médio $38,4 \%$ maior que os $50 \%$ da população com os menores rendimentos, tendo também o índice de Gini alcançado o valor de 0,525 em 2016 (IBGE, 2017).

$7 \quad$ Apesar de muitos dos que mobilizaram estes grupos a se manifestarem nas ruas eram indiciados e condenados em diversos processos de corrupção.
} 
aprovar ainda em 2017. Há também uma Contrarreforma da Previdência que dificultaria a recepção por parte da população em receber os benefícios desta - financiados por essa mesma população - e nossa Reforma do Ensino Médio, que como iremos demonstrar em seguida, aponta para uma adequação da nossa educação às exigências do Banco Mundial, sinalizando para uma privatização da educação e para uma redução da qualidade da oferta educacional às camadas mais populares.

Assim, se por um lado às camadas populares irão pagar o pato ${ }^{8}$ com as novas medidas políticas implantadas, por outro a classe empresarial é extremamente beneficiada com essas políticas, e com outras como por exemplo a Medida Provisória do Refinanciamento de Dívidas $^{9}$ e a Medida Provisória que garante isenção fiscal por 25 anos às multinacionais petroleiras ${ }^{10}$, o que literalmente mostra como o fluxo das riquezas se dará nesse ciclo político.

Todas essas ações, diante da sua impopularidade seriam um risco para qualquer governo em nosso frágil modelo democrático, pois, teria repercussões em eleições futuras, mas não é problema algum para um governo que não foi eleito, que não passou pelo crivo das urnas, configurando, então, a relação essencial que existe entre estas Contrarreformas e o processo de impeachment como golpe que se inicia nesse ciclo.

Todavia, tais ações tem como um elemento de contradição a resistência dos setores populares atingidos por estas. Essa resistência da população vem ocupando às ruas desde o impeachment e quando são anunciadas as medidas, com destaque para a grande Greve Geral ocorrida em 24 de abril contra a aprovação da Reforma Trabalhista e da Previdência. Essa movimentou milhões de pessoas no país inteiro em grandes atos e parou a produção de forma significativa para a economia, de modo a ser comparada com a Greve Geral de 1917. Ocorreram também ocupações realizadas por estudantes secundaristas e essas atingiram milhares de escolas em todo país reivindicando a revogação da Medida Provisória nº 746/2017 (Contrarreforma do Ensino Médio) e pela discussão de forma ampla com a sociedade sobre o Ensino Médio que eles, sujeitos dessa Educação, querem. Contudo, é necessário afirmar que a imprensa hegemônica pouco destaque deu a esses movimentos e quando o deu foi de forma pejorativa.

\footnotetext{
8 Durante as manifestações em favor do Impeachment, a Federação das Indústrias do Estado de São Paulo construíram um grande boneco de um pato sob a simbologia de que eles, grandes empresários, não pagariam o preço da crise financeira que repercutia no país.

9 Medida Provisória ${ }^{\circ} 783 / 2017$, segundo estimativa do jornal El País governo abrirá mão de mais de 500 milhões de reais ao empresariado brasileiro. Disponível em: 〈https://brasil.elpais.com/brasil/2017/08/15/politica/1502754070 555329.html> Acesso em 06 dez. 2017.

10 Medida Provisória 795/2017, que segundo estimativa de especialistas consultados pela Revista Época, pode gerar uma isenção fiscal de mais de 1 trilhão de reais, o que seria mais que o dobro do anunciado pelo governo como economia nos gastos públicos com a Reforma da Previdência Disponível em: <http://epoca.globo.com/ciencia-e-meio-ambiente/blog-do-planeta/noticia/2017/12/mp-795-1-trilhao-demotivos-para-ser-contra.html $>$ Acesso em 06 dez. 2017.
} 
Apesar de toda a resistência e desse quadro de mobilização o governo tem aprovado todas as medidas, contra estudantes e trabalhadores, sem considerar a voz das ruas, ouvindo apenas àqueles que tem o maior interesse na aprovação destas, a classe que vive do trabalho alheio e do capital financeiro.

A educação é sempre um elemento central de ataque das políticas de retrocesso social diante do espaço que a escola ocupa ao que Gramsci (1981) chama de sociedade civil, graça às suas possibilidades de conquista de contra hegemonia através do convencimento. Portanto, mudar a escola brasileira tem uma importância central para os planos de quem compõe a atual hegemonia no Estado brasileiro, pois ela tanto pode ser um espaço de emancipação dos sujeitos que vivem do trabalho - contra essa situação de desigualdades, como pode ser um instrumento de conformação e de manutenção destas (KUENZER, 2010).

Sendo assim, é neste quadro de retrocesso social que vem ocorrendo por meio de manobras do Estado brasileiro, que as políticas são formuladas e aprovadas por um governo não eleito, mas que em aliança com um congresso conservador e patrocinado pelas camadas mais ricas deste país, mesmo reprovadas pela maioria da população e implementadas a revelia dos sujeitos alvos dessas ações estatais, que a Contrarreforma do Ensino Médio foi aprovada e vem sendo implementada em todo território nacional.

\section{ENSINO MÉDIO, EDUCAÇÃO PROFISSIONAL E SUAS DUALIDADES: ENTRE FARSAS E TRAGÉDIAS}

A educação em nosso país tem uma marca histórica que é a dualidade. Por um lado nós temos uma educação ofertada para os filhos das camadas mais ricas da sociedade, sendo uma educação que irá preparar estes jovens para serem dirigentes dessa sociedade, por outro lado temos uma educação ofertada aos filhos daqueles que vivem do trabalho que será uma educação voltada para que estes continuem a sustentar o atual modelo social mantendo-se nas camadas de mais baixo poder aquisitivo (MOURA, 2010).

Essa dualidade por sua vez apresenta outras, sendo uma destas a separação entre a teoria e prática, que tem como base a divisão social do trabalho - em trabalhos intelectuais e trabalhos manuais. Assim, a educação dos filhos das classes dirigentes será uma de base profundamente teórica para exercer esses trabalhos intelectuais, com maiores salários, melhores perspectivas, preparando-os para à direção da sociedade, ou seja em cargos públicos de alto nível, enquanto aos filhos das camadas populares será ofertada uma educação restrita para que estes exerçam os trabalhos manuais, mais desgastantes, com os menores salários e sem às 
perspectivas de intervenção na direção da sociedade, bem como com as piores condições de trabalho.

Como já mencionamos, o Ensino Médio é tido em nosso tempo histórico como uma etapa de preparação para o Ensino Superior, carecendo, então, de uma identidade própria (MOURA, 2010). Assim, dado o quadro de dualidades apresentado e a limitação brasileira de acesso ao Ensino Superior, o ensino médio, será etapa de passagem apenas para aqueles que tiveram melhores condições materiais, restando à maioria da população ter esta etapa como encerramento da vida escolar e dos estudos ${ }^{11}$, quando conseguem concluí-la.

Para superar essa carência de identidade e essas dualidades históricas há uma alternativa em construção, um Ensino Médio Integrado à formação profissional que pretende à formação humana integral, educar para o trabalho e para à vida com vistas a emancipação dos sujeitos. Essa proposta tem como inspiração à Escola Unitária de Gramsci (1981), as concepções de Politecnia de Saviani (1989), e as propostas de Escola Politécnica no período de transição social quando os pedagogos soviéticos, como Pistrak (2005), se dedicaram a ver as possibilidades de uma formação que não apartasse o trabalho da vida.

O Ensino Médio Integrado pretende na mesma oferta educacional, durante o mesmo curso, e nos limites da Lei de Diretrizes e Base da Educação do Brasil, Lei no 9.394/1996, garantir a formação básica exigida pelo ensino médio. Nesta as disciplinas propedêuticas seriam acrescidas de disciplinas de formação técnica e profissional, onde os estudantes receberiam ao final dessa etapa de transição -, a habilitação profissional. Essa modalidade apresenta diversas limitações no que tange seu horizonte, assim como, os pedagogos russos reconheciam em 1929 a importância de superar a separação das colunas de disciplinas teóricas e práticas, a perspectiva da Politecnia quer a superação da separação entre disciplinas propedêuticas e técnicas, porém, a ausência de condições objetivas para essa superação não é impedimento para a construção de uma etapa transitória que não perde de vista esse horizonte (MOURA; LIMA FILHO; SILVA, 2015).

Essa alternativa está longe de ser majoritária em nossa Educação, segundo o Anuário Brasileiro da Educação Básica de 2018 corresponde a apenas a 5\% (TODOS PELA EDUCAÇÃO, 2018). A grande maioria dos nossos jovens está sendo educada naquele ensino médio que carece de identidade, de interesse, considerando-se que a maioria dessa oferta se dá

\footnotetext{
11 Segundo o anuário da Educação Básica 2017, apenas 6,9\% dos estudantes oriundos da população mais pobre do país tem acesso ao Ensino Superior, e a taxa líquida de matrícula deste, no geral, é de apenas $18 \%$. Optamos por utilizar esses dados do Anuário de 2017 pois no ano seguinte houve alteração na forma de cálculo, consideração a população mais pobre como sendo um quartil da população brasileira, não permitindo a comparação adequada. <https://www.todospelaeducacao.org.br//arquivos/biblioteca/anuario_brasileiro_da_educacao_basica_2017_com_marcadores.pdf > Acesso em 06 dez. 2017.
} 
em Escolas Públicas em sua boa parte carente também de estrutura e condições adequadas de funcionamento. O que faz da mudança do Ensino Médio uma pauta da sociedade já há bastante tempo.

Aproveitando-se, dessa reconhecida necessidade de mudança no Ensino Médio, e diante de um cenário de baixos índices em avaliações de larga escala dos organismos multilaterais, como o Programa Internacional de Avaliação de Alunos (PISA), e daquelas construídas como base nas recomendações destes, como o Índice de Desenvolvimento da Educação Básica (IDEB), o governo Temer acelera a Contrarreforma do Ensino Médio que estamos a discutir nesse trabalho.

As avaliações de larga escala vêm se constituindo ao longo das últimas décadas, nesse período de hegemonia do pensamento neoliberal, como instrumento muito mais de justificativa de construção de políticas de austeridade e de contrarreformas, do que enquanto instrumento de avaliação educacional, esse uso é característico do que Afonso (2013) chama de Estado-Avaliador.

Nesse sentido, o Estado-Avaliador preocupar-se-á muito mais com os índices das avaliações de larga escala da educação, do que com o processo educacional em si. Nesse diapasão, a Contrarreforma do Ensino Médio aponta para isto ao ter como Base a Construção de uma Base Nacional Curricular Comum (BNCC), que apesar de ainda não definida já sugere a priorização de disciplinas que são o foco dessas avaliações, o próprio texto do Ministério da Educação no site do "Novo Ensino Médio" já aponta essa contradição ao dizer que o objetivo da Base Comum é "[...] promover a elevação da qualidade do ensino no país por meio de uma referência comum obrigatória.”(BRASIL, 2017), ou seja, a elevação da qualidade da educação no país que envolve estrutura, formação docente, concepções de educação, e mais tantos fatores, é resumida a uma base de disciplinas que irão colaborar com a mudança dos índices nas

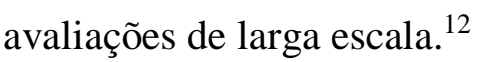

Ao aumentar o peso das disciplinas que repercutem nesses testes temos como consequência a redução do tempo para as disciplinas que colaboram com a construção de um pensamento crítico. A Base Comum ${ }^{13}$ hoje seria responsável por metade da carga horária do

\footnotetext{
12 Apesar da problemática, é importante ressaltar que o Ensino Médio Integrado, ofertado na Rede Federal de Ensino, tem obtido notas no PISA similares a países como Coréia do Sul e Canadá, simulando sua nota com de um país, teria ficado a frente de países como Coreia do Sul, Estados Unidos e Alemanha (IFB, 2016). Dessa forma, é importante notar que já temos um Ensino Médio no Brasil que pode servir de modelo e ser expedindo. Importante lembrar que essa oferta na Rede Federal não tem foco ou preocupação com as notas das avaliações em larga escala, mas sim aquele horizonte politécnico já citado.

13 A Base Comum, conforme a legislação, será definida a partir do Conselho Nacional de Educação, sendo este composto por vários atores interessados e formuladores da Reforma do Ensino Médio, como por exemplo o Movimento Todos Pela Educação, Instituto Ayrton Senna, Confederação Nacional da Industria, Federação das Industrias do Estado de São Paulo e reitores e investidores de grandes grupos privados do mercado da educação. É importante destacar que durante o governo Temer ocorreu a revogação de mandatos de Conselheiros o que foi alvo de muitos protestos.
} 
Ensino Médio, 1200 horas, a outra metade da formação seria a partir dos chamados itinerários formativos, que serão combinações de conteúdos dos quais os alunos escolherão de acordo com seu interesse e afinidade, e é nessa liberdade de escolha que se pauta a propaganda ideológica do governo.

Tratamos essa questão como propaganda ideológica, pois o texto da Contrarreforma não garante a oferta de todos os itinerários pela mesma escola, e diante das limitações de recursos e de estrutura física/material/humana das escolas públicas, o cenário aponta para que ao invés da liberdade de escolha, os sujeitos dessa reforma, como bem descreveu Motta e Frigotto (2017), estudantes de escolas públicas das camadas populares de nosso país, farão uma escolha compulsória conforme o itinerário que sua escola puder ofertar.

Essa medida reforça a dualidade característica de nossa educação, pois, as escolas privadas terão maiores condições, tanto para ofertar todos os itinerários, quanto para compensar a ausência de conteúdos ocasionados pela restrição da Base Comum, segundo Ramos, em entrevista:

Uma Escola de elite pode tranquilamente optar por oferecer todos os itinerários e fazer arranjos que permitam o aprofundamento da formação geral, até porque essas escolas não têm problemas de espaço físico e nem falta de professor. São as escolas dos sistemas públicos que vão fazer efetivamente a redução. Então, você tem reiterada e legalizada uma dualidade por dentro do sistema de ensino (REVISTA POLI, 2017, p.8).

É importante lembrar que, essa perspectiva dos problemas de estrutura de nossa educação pública nos permitem concluir que geram dificuldades de oferta dos diversos itinerários e é reforçada por outra ação deste governo que foi a aprovação da Emenda Constitucional no 95/2016 que congela o gasto público com a área social, dentro desta está a educação, por 20 anos. Assim, teremos um quadro agudizado de maior precarização das nossas escolas públicas, o que aprofundará mais ainda esse fosso de dualidades que limita e delimita cada vez mais a qualidade social da nossa escola pública. Por isso, faz sentido a afirmação do governo em sua página do Novo Ensino Médio ao afirmar que sua ação para melhoria da qualidade na educação será criar a Base Comum - para melhorar os índices na avaliação de larga escala - e só.

Um dos itinerários formativos que constam do rol da Lei $\mathrm{n}^{\circ} 13.415$, de 2017, que é a conversão da Medida Provisória que institui a Contrarreforma em Lei, é a formação técnica. Porém, ao revogar o Parágrafo $2^{\circ}$ e alterar o $3^{\circ}$ do art.36 da LDB, essa formação técnica segue em rumo diverso daquele percorrido pelo Ensino Médio Integrado. Nesse sentido, no primeiro caso tínhamos garantido que essa formação se daria respeitando a carga-horária mínima da formação geral, as 2.400 horas, ou seja, tínhamos uma ampliação do tempo de formação. Com 
essa supressão e o novo modelo de Base Comum mais o itinerário, toda a formação se dará nessas 2.400 horas, logo, com redução da formação geral. No segundo caso, o parágrafo terceiro garantiria a equivalência entre esta formação técnica e as demais formações de nível médio, podendo com a conclusão deste, o estudante ingressar no Ensino Superior.

Somadas as questões da redução do tempo de formação geral para os estudantes que optarem pelo itinerário da formação técnica, com a projeção da impossibilidade desses alunos não poderem optar pelos diversos itinerários em função das possibilidades de nossas escolas públicas, e ainda assim quando puderem não ter acesso aos conteúdos dos demais itinerários, Ramos (JÚNIA, 2017) e Motta e Frigotto (2017), afirmam que essa Contrarreforma do Ensino Médio nos coloca no patamar de dois modelos anteriores, o dos anos de 1960 e o dos anos 1970.

A semelhança ao modelo dos anos 1960, alvo de várias críticas pela ausência de equivalência entre as modalidades de ensino, em nosso caso ocorre quando os estudantes não terão caminhos formativos diferentes com os itinerários, já o segundo modelo, com sua educação profissional compulsória sem a devida estrutura para as escolas terão como resultados apenas um: a redução da carga-horária da formação geral.

A Educação Profissional, sob essa perspectiva, poderá reforçar ainda mais o Ensino Médio enquanto limite da formação educacional das classes populares, pois, àqueles estudantes que optarem por este itinerário não terão acesso adequado aos conteúdo dos vestibulares, o que de certa maneira restringirá mais ainda o acesso dos sujeitos ao Ensino Superior. Isso nos lembra mais um episódio da nossa história de luta pela educação, quando no período que antecedeu o modelo dos anos 1970 e a população brasileira estava reivindicando acesso às universidades, e como resposta o governo editou o Ensino Médio com formação técnica compulsória. Assim, a História parece se repetir não mais como farsa, mas sim como tragédia (MARX, 2008a).

Outro aspecto muito importante que mostra como, na perspectiva da Educação Profissional, esta Contrarreforma segue o caminho da precarização e os rumos contrários aos da Politecnia e da formação humana integral é a possibilidade de contratação de professores, exclusivamente para as disciplinas do itinerário formação técnica, profissionais sem a condição mínima exigida para lecionar em nosso país que é o Ensino Superior, o que a lei chama de profissionais de notório saber.

Se por anos o debate sobre a formação docente nos marcos da Educação Profissional tem sido uma questão de muitas alternativas e divergências, sobre as possibilidades e as formas de realização desta, seja por uma graduação específica, por inserção na formação 
inicial, por especializações por área técnica específica, formação continuada, o governo resolve o problema da dor de cabeça cortando a cabeça. Assim, não há preocupação com a vida. Tal medida reflete uma grande desvalorização da profissão de professor e com a formação humana dos sujeitos jovens que são os alvos principais do ensino médio.

Essa possibilidade somada à nova legislação trabalhista, aprovada no mesmo contexto de contrarreformas em que foi imposta a do Ensino Médio, que possibilita o contrato de jornada intermitente, onde o trabalhador é cadastrado em um banco na empresa, convocado por demanda e recebe apenas pelas horas trabalhadas, sem pagamento de repouso ou afins, o professor não receberá salário pelas horas de planejamento e atividades extraclasse, precarizando ainda mais a educação em nosso país, preparando sujeitos também para trabalhos precarizados.

Tal projeção já é uma realidade, por exemplo no ensino superior, onde a Faculdade Estácio de Sá, logo após a vigência da nova legislação trabalhista demitiu 1.200 professores para reinseri-los nesse novo modelo ${ }^{14}$.

Essa situação, em um quadro de desemprego estrutural (MESZAROS, 2011) onde mais de 12\% dos brasileiros encerrarão 2017 desempregados (IBGE, 2017a). Isso, faz com que os trabalhadores se sujeitem à essas novas jornadas de trabalho mais desgastantes, ainda mais sob a perspectiva de maior competitividade, pois com o notório saber, mais profissionais estarão habilitados à docência na Educação Profissional, repercutindo na formação que será ofertada para nossa juventude.

A Contrarreforma do Ensino Médio só terá vigência oficial no ano subsequente à aprovação da BNCC, que conforme a presidência do Conselho Nacional de Educação indica ${ }^{15}$, seria no início de 2018. Logo, o novo modelo será implementado a partir de 2019. Todavia, na Educação Profissional o MedioTec, que é a vertente do Programa de Governo para Educação Profissional que mais recebeu recursos nos últimos 5 anos - mais de 19 bilhões de reais até 2015 (BRASIL, 2017), pela via do Programa Nacional de Acesso ao Ensino Técnico e Emprego (PRONATEC), está possibilitando um adiantamento às medidas da Contrarreforma, seus objetivos e reflexos, por esse motivo trataremos desse assunto de modo específico no tópico a seguir.

\footnotetext{
14 Estácio de Sá demite 1,2 mil professores após reforma trabalhista. Disponível em:

$<$ http://www1.folha.uol.com.br/mercado/2017/12/1940980-estacio-de-sa-demite-12-mil-professores-apos-reformatrabalhista.shtml> Acesso em $06 \mathrm{dez} 2017$.

15 Diretrizes para currículo do ensino médio serão concluídas só no ano que vem. Disponível em: <http://agenciabrasil.ebc.com.br/educacao/noticia/2017-11/diretrizes-para-curriculo-do-ensino-medio-serao-concluidas-so-no-ano-que> Acesso em 06 dez 2017.
} 


\section{MÉDIOTEC ENQUANTO CATALISADOR DA CONTRARREFORMA NA EDUCAÇÃO PROFISSIONAL}

O Pronatec, até 2016, vinha se configurando como a principal política de Educação Profissional do governo brasileiro. Isso pode ser confirmado tanto pelos dados supracitados, dos valores investidos, quanto pela própria propaganda política do governo impedido de continuar, como também pelo número de matrículas, que segundo o site do Programa, até 2015 tínhamos mais de 9 milhões de matrículas.

Apesar dessa centralidade, ele é considerado tanto pelos pesquisadores que defendem a Educação Profissional sob a perspectiva de uma formação humana integral, quanto por boa parte dos sindicatos dos trabalhadores da educação profissional como um retrocesso nas políticas de Educação Profissional do governo que o implantou. Tais críticas tem como fundamento o foco em cursos de curta duração, que impossibilitam uma formação humana de qualidade para a classe que vive do trabalho no Brasil e que precisa dessa para sua emancipação. Essa é classe merecedora de ações do Estado e pela quantidade de recursos públicos que são diretamente investidos na esfera privada através desse programa ${ }^{16}$ não é para ela que os recursos se dirigem. Nesse direcionamento dado pelo Estado o que se ver configurado é a privatização dos bens públicos, pois além dos recursos o governo permite que as Instituições ofertantes imprimam sobre o processo educativo suas concepções de educação pela contratação de empresas privadas para dirigir os rumos das escolas.

O Pronatec, a partir da sua formatação, demonstra ter como fundamento a teoria do capital humano (SCHULTZ, 1973). Esta afirma ser necessário investir na formação das pessoas considerando-as como recursos e que essa ação trará retorno na produção o que em nosso presente quadro de desemprego estrutural e hegemonia do pensamento neoliberal, torna-se o fundamento da tese da empregabilidade, nesse sentido:

[...] a defesa da qualificação como forma de superar o desemprego, apresenta uma outra função importante para a tese da requalificação, dentro da irradiação da ideologia neoliberal, qual seja, a transferência da responsabilidade do emprego para o trabalhador, que passa a agora a ter que manter-se constantemente qualificado e se requalificar para manter sua condição de empregabilidade e assim garantir trabalho. (SANTOS, 2018, p. 51)

Essa composição de teses que fundamentam o Pronatec além de mirar a formação, exclusivamente, para a perspectiva do mercado, sem considerar: as necessidades históricas das camadas populares brasileiras, a importância de um letramento social desses trabalhadores para

16 Segundo Melo (2015) até 2014 mais de $73 \%$ dos recursos do Pronatec foram destinados às esferas privadas. 
sua intervenção e um mundo trabalho marcado pela desigualdade de classes, está desconexa com o projeto de desenvolvimento do país. Posto que se não a postos de trabalho que melhore o atual quadro de desemprego, o Pronatec serve apenas para aumentar a competitividade entre os trabalhadores em busca dos mesmos postos de empregos, saindo como vitoriosos apenas os empresários do mercado da educação. Afirmação essa comprovada tanto por recente pesquisa do IBGE (2014) que afirma que as pessoas oriundas do Pronatec não têm melhorado suas condições de emprego, quanto pelos números citados de repasse para instituições privadas.

Sob essa perspectiva, Lima (2017) afirma que o Pronatec em seu desenvolvimento e concepção vai de uma formação para o mercado para necessariamente um mercado da formação. Para nós o Pronatec é o que diz Santos:

[...] em sua essência [...]após a retirada da fumaça do discurso ideológico e eleitoral, este Programa se apresenta como uma forma de irradiar o pensamento hegemônico, haja vista a reprodução dos discursos da empregabilidade, da requalificação da força de trabalho e da teoria do capital humano. Sendo este Programa também uma forma destes grupos hegemônicos ocuparem mais trincheiras, mais instituições e ampliarem a força daquelas que já exercem sua hegemonia, avançando sobre as dos grupos contra-hegemônicos, graças às re/delimitação entre esfera pública e privada, causada pelo PRONATEC e suas possibilidades de acúmulo de capital via fundo público. (SANTOS, 2018, p. 66).

Com a recém mencionada mudança de governo, advinda do Golpe político de 2016, e a política de redução de gastos com os investimentos sociais com saúde e educação, o Pronatec vem perdendo significados mas ganhando outros. O foco do governo passa a ser formatar o Pronatec para se adequar a sua nova proposta de Ensino Médio. Nesse sentido, editam o MedioTec, que conforme o próprio governo é uma ação estratégica do Pronatec. Esse segundo o portal do MEC o "MedioTec oferece 107.465 vagas em 131 cursos técnicos gratuitos a alunos da rede pública de ensino" apenas para o segundo semestre de $2017^{17}$, o que corresponderia a um investimento de aproximadamente 700 milhões.

Essa nova forma de Pronatec serviria de catalisador da Contrareforma do Ensino Médio, que por questões legais só pode ser implantada um ano após a decisão da BNCC, o que seria no mínimo em 2019. Assim, ela adianta a Reforma em diversos aspectos, o primeiro na questão da concepção de Educação Profissional para o nível médio. Pois segue o caminho contrário à possibilidade de integração do Ensino Médio à Educação Profissional, numa perspectiva de superar a separação entre disciplinas propedêuticas e disciplinas técnicas, pois

17 “Em 2017, Pronatec ofertará quase 10 vezes mais vagas em cursos técnicos a alunos do ensino médio.” Disponível em: <http://portal.mec.gov.br/ultimas-T/209-564834057/52191-estao-abertas-as-inscricoes-para-cursos-tecnicos-gratuitos> Acesso em 06 dez 2017. 
tem como base a concomitância, marca da Reforma no período do governo Fernando Henrique Cardoso (anos 1990) com o Decreto n $2.208 / 1997$, que impedia essa integração.

$\mathrm{O}$ atual modelo de Ensino Médio Integrado põe em cheque os fundamentos da atual contrarreforma e coloca estes em nível de ideologia, pois, apesar de não ter como foco a preparação para o Exame Nacional do Ensino Médio, as Escolas Públicas Federais, que são as maiores e principais ofertantes do Ensino Médio Integrado tiveram excelentes resultados, que por sinal foram suprimidos propositalmente pelo governo do ranking para evitar tais discussões, sendo inserida somente após denúncias e manifestações. ${ }^{18}$ Dessa forma, tais escolas que tem um maior aporte de recursos que as demais que ofertam o Ensino Médio de forma pública, demonstram que o problema não é a oferta pública, mas sim a ausência de investimento por parte do Estado brasileiro na educação básica e notadamente na última etapa.

O segundo aspecto em que ele adianta a Contrareforma é na perspectiva da privatização do itinerário formativo da formação profissional, pois, com a Emenda que congela os gastos com Educação por 20 anos, não será possível - sem o investimento adequado construir laboratórios e adquirir estrutura para ofertar esses novos conteúdos. Sendo assim, o governo, assim como já vinha fazendo no Pronatec, irá privatizar parte da oferta educacional pública, encaminhando os jovens para instituições privadas que irão receber recursos públicos para ofertar educação sob a perspectiva e concepção dessas, ou seja, as do mercado. Mas, onde está esse mercado ${ }^{19}$

O Medio-tec trata de avançar com as concepções de educação e trabalho do Pronatec rumo ao Ensino Médio. Nesse sentido, Frigotto em entrevista à Revista Poli chama esse movimento de "pronatequização do ensino médio" (JÚNIA, 2017, p. 7).

É importante destacar também que o foco da oferta deste Programa tem sido os cursos de Educação a Distância ${ }^{20}$, pois bem, se as disciplinas técnicas que tem maior apelo à atividade prática serão ofertadas à distância, a reformatação do Pronatec pelo governo terá como característica uma maior precarização da Educação Profissional.

Dessa forma, consideramos o Medio-tec como catalisador da Contrarreforma do Ensino Médio, adiantando seus efeitos na Educação Profissional, retomando princípios de outra Contrarreforma do Ensino Médio, desta vez, aquela dos anos 1990, ao aproximar-se da

\footnotetext{
18 Inep admite equívoco e diz que divulgará nota do Enem dos institutos federais. Disponível em: <http://agenciabrasil.ebc.com.br/educacao/noticia/2016-10/inep-admite-equivoco-e-diz-que-divulgara-nota-do-enem-dos-institutos> Acesso em 06 dez 2017.

${ }^{19}$ A síntese dos indicadores do IBGE em 2017, aqui já referenciada, apresenta um forte aumento da desocupação (11,3\%), da ocupação por conta própria dos trabalhadores $(24,7 \%)$, dos trabalhadores sem carteira assinada $(18,5 \%)$ e da taxa de subutilização do trabalho (20,8\%). Em 2016, do total de pessoas desocupadas, mais da metade (54,9\%)eram jovens de 16 a 29 anos de idade.

20 Em Consulta à distribuição das vagas do estado com mais vagas, Minas Gerais, constatamos que neste de um total de 19.803, apenas 816 são para cursos presenciais, sendo todas estas em instituições privadas, esse padrão segue nos demais estados. Disponível em: <http://portal.mec.gov.br/mediotec/mediotec-nos-estados> Acesso em 06 dez 2017.
} 
perspectiva da concomitância e afastar-se, ainda mais, da integração e de uma perspectiva politécnica de formação humana integral.

\section{SÍNTESES, TAREFAS E NOVAS CONTRADIÇÕES}

As contrarreformas que são marcas do governo que inicia esse novo tempo histórico com o golpe político-jurídico e midiático de 2016, no Brasil, não são processos iniciados nesse governo necessariamente. Mas, foram com ele acelerados como reação às diversas reformas realizadas no período antecedente. Há uma estreita relação entre aquelas contrarreformas e o processo de impeachment que é o centro desse processo, pois a amplitude do retrocesso social e da retirada de direitos que ocorrerá caso todas essas sejam aprovadas e implementadas, não poderia ser realizada por nenhum governo eleito diante da impopularidade de tais ações, apesar da fragilidade de nossa democracia.

Essas contrarreformas vêm para atender as demandas do capital, na Educação Profissional, atendendo às novas demandas de qualificação, para garantir processos de proletarização passiva (OFFE, 1984), diante do desemprego estrutural via ampliação o mercado educacional.

A combinação entre a redução dos gastos com educação pública nos próximos vinte anos, aprovada pela Emenda 95, com o cenário de ampliação da espoliação dos trabalhadores com a Contrarreforma trabalhista e com a Reforma do Ensino Médio, apontam para uma redução na qualidade social (DOURADO; OLVIEIRA; 2007)) da oferta pública. Oferta essa, na qual se insere - a maioria da população brasileira em sua vertente de privatização e no campo da Educação Profissional na estrita adequação às demandas do mercado - seja ele de trabalho ou do mercado educacional. Tudo isso projeta um quadro de ampliação das desigualdades sociais e das dualidades como marca históricas da Educação Profissional do nosso país.

Todavia, esse processo não segue sem as impressões digitais dos movimentos sociais, sem a resistência do Movimento Estudantil, sem Greves e Mobilizações dos Trabalhadores em Educação e seus sindicatos. Nessa disputa por hegemonia, em que a educação, a escola, o elemento de vida destes atores - estudantes e trabalhadores se encontram, são importantes espaços de disputa em nossa sociedade moderna.

Após anos de reformas sociais, de pouca ousadia em avançar com os projetos de uma educação emancipatória para que os filhos das camadas populares pudessem disputar a direção da sociedade e sem avançar para disputar um projeto de educação que reflita o acúmulo do debate sobre Politecnia, Formação Humana Integral, Escola Unitária e Omnilateralidade, o campo contra-hegemônico dos trabalhadores e pesquisadores em Educação Profissional do 
Brasil, encontra nesse momento um espaço propício para mostrar as contradições, ousando lembrar que acima da luta por Reformas existe uma luta por Revolução, e/ou contra a barbárie.

\section{REFERÊNCIAS BIBLIOGRÁFICAS}

AFONSO, Almerindo. Mudanças no Estado Avaliador: comparativismo internacional e teoria da modernização revisitada. Revista Brasileira de Educação, Rio de Janeiro, v. 18, n. 53 2013.

BRASIL. Novo Ensino Médio Dúvidas. Brasília, 2017. Disponível em: <http://portal.mec.gov.br/component/content/article?id=40361>. Acesso em: $06 \mathrm{dez} .2017$.

BRASIL. Consulta ao E-sic de protocolo 23480014302201761 realizado pela CGU na Secretaria de Educação Profissional e Tecnológica. 2017b.

Os intelectuais e a organização da cultura. Tradução de Carlos Nelson Coutinho. 8. ed. Rio de Janeiro: Civilização Brasileira, 1991.

IBGE. Educação e qualificação profissional: 2014. Rio de Janeiro: IBGE, 2017. Disponível em: < https://biblioteca.ibge.gov.br/visualizacao/livros/liv100061.pdf> Acesso em: 15 fev. 2018.

Síntese de indicadores sociais: uma análise das condições de vida da população brasileira. 2017. IBGE, Coordenação de População e. Indicadores Sociais. Rio de Janeiro: IBGE, 2017.

Pesquisa Nacional por Amostra de Domicílios Contínua: Trimestral - PNAD Contínua. 2017a. Disponível em: <https://www.ibge.gov.br/estatisticasnovoportal/sociais/trabalho/2217-np-pesquisa-nacional-por-amostra-de-domicilios-continuatrimestral/9173-pesquisa-nacional-por-amostra-de-domicilios-continuatrimestral.html?\&t=resultados $>$. Acesso em: 06 dez. 2017.

IFB. Rede Federal é destaque na principal avaliação da educação básica do mundo. [Disponibilizado em 2016, na internet] 2016. Disponível em: < http://www.ifb.edu.br/reitori/12838-rede-federal-e-destaque-na-principal-avaliacao-daeducacao-basica-do-mundo> Acesso em: 11 ago. 2017.

JÚNIA, Raquel. Mediotec: a mesma qualificação para a mesma classe social. POLI: saúde educação trabalho. Rio de Janeiro, n. 51, p. 6 -11, mai./jun. 2017.

KUENZER, Acácia. As Políticas de Educação Profissional. Uma reflexão necessária. In: MOLL, Jaqueline (Org.) Educação Profissional e Tecnológica no Brasil Contemporâneo. Desafios, Tensões e Possibilidades. Porto Alegre, 2010. p. 58 - 79.

LUKACS, George. História e Consciência de Classe: Estudos sobre a dialética marxista. São Paulo: Martins Fontes, 2003.

MANCE, Euclides. O Golpe - Brics, Dólar e Petróleo / Euclides Mance. Passo Fundo: IFIBE, 2018. 
MARX, Karl . Contribuição à crítica da Economia Política. São Paulo: Expressão Popular, 2008.

MARX, Karl. 18 Brumário e Cartas a Kugelmann. Rio de Janeiro: Paz e Terra, 2008a.

MELO, Ticiane Gonçalves Sousa de. O Pronatec e o Processo de Expansão e Privatização DA Educação Profissional no Brasil. 2015. 138f. Dissertação (Mestrado em Educação Profissional) - Instituto Federal de Educação, Ciência e Tecnologia do Rio Grande do Norte, Natal, 2015.

MÉSZÁROS, István. A Crise Estrutural do Capital. Trad. Francisco Raul Cornejo [et al.]. São Paulo: Boitempo Editorial, 2011

MOTTA, Vânia Cardoso da; FRIGOTTO, Gaudêncio. Por que a urgência da reforma do ensino médio? Medida provisória no 746/2016 (Lei nº 13.415/2017). Educ. Soc., Campinas v. 38,n. 139, p. 355-372. 2017.

MOURA, Dante Henrique. Ensino Médio e educação Profissional dualidade histórica e possibilidade de integração. In: MOLL, Jaqueline (Org.) Educação Profissional e Tecnológica no Brasil Contemporâneo. Desafios, Tensões e Possibilidades. Porto Alegre, 2010. p. $58-79$.

; LIMA FILHO, Domingos Leite; SILVA, MÔNICA RIBEIRO. Politecnia e formação integrada: confrontos conceituais, projetos políticos e contradições históricas da educação brasileira. Rev. Bras. Educ. vol.20, n.63, p. 1057-1080. 2015.

OFFE, CLAUS. Problemas estruturais do estado capitalista. Rio de Janeiro: Tempo Brasileiro, 1984.

PISTRAK, Moisey M. Ensaios sobre a Escola Politécnica. São Paulo: Expressão Popular, 2015.

SANTOS, Shilton Roque dos. Avaliação participativa de resultados sociais do PRONATEC Campo. 2018. 168f. Dissertação (Mestrado em Educação Profissional) Instituto Federal de Educação, Ciência e Tecnologia do Rio Grande do Norte, Natal, 2018.

SAVIANI, Dermeval. Sobre a concepção de politecnia. Rio de Janeiro: FioCruz, Politécnico da Saúde Joaquim Venâncio, 1989.

SCHULTZ, T. O capital humano: investimento em educação e pesquisa. Trad. de Marco Aurélio de M. Matos. Rio de Janeiro: Zahar, 1973.

TODOS PELA EDUCAÇÃO. Anuário Brasileiro da Educação Básica. 2018. São Paulo: Moderna, 2018. 